\title{
The Evaluation Index System of Technology Maturity: Taking Hybrid Electric Vehicle as an Example*
}

\author{
Jianhua LIU ${ }^{1}$, Junchang JI ${ }^{1}$, Shuqi WANG ${ }^{1}$, Zhaohua JIANG ${ }^{2}$, Lei HUANG ${ }^{2}$ \\ ${ }^{1}$ School of Management Engineering, Zhengzhou University, Zhengzhou 450001, China, ljh@ zzu.edu.cn; \\ ${ }^{2}$ School of Public Management and Law, Dalian University of Technology, Dalian 116023, China, jiang_zhaohua@163.com
}

\begin{abstract}
Technology maturity, as an important indicator to measure development state and future trends of technology, can effectively control the risk of technology research and application. It is widely used in technology prediction of national defence, hightech and strategic emerging industries. Based on a comprehensive review of the existing evaluation method and application research of technology maturity, a multi dimension evaluation model is proposed, including the proportion of papers, patents and references, the density and efficiency of patent network, a total of ten indicators, which overcomes the defect of single index. And taking the hybrid electric vehicle as an example, the calculated results show that, the hybrid electric vehicle technology has been mature in 2003, and entered into a new boom period after 2009, because of the new breakthroughs in scientific research.

Index Terms - technology maturity; evaluation index system; hybrid electric vehicle
\end{abstract}

\section{Literature review of technology maturity}

In abroad, the research of the technology maturity has begun long time ago, the United States is the first to study and analysis this theory ${ }^{[1]}$. Domestic scholars have researched this theory since the $1990 \mathrm{~s}$. Overall, the existing researches on technical maturity can be classified into the following several direction.

\subsection{Based on the TRL technical maturity level evaluation research}

In the 1970s, NASA put forward the Technology Readiness Level (TRL) to divide the technical maturity into nine grades as the initially standard level to evaluate the maturity of the new technology. This is the first evaluation metrics of technical maturity. Mankins first tried to use TRL to establish the difficulty index and the methodology of maturity [2]. Mr. William in the research on the basis of research of NASA's TRL invented the product technical maturity calculator ${ }^{[3]}$. In domestic, Lan Yuanpei and Guan Zhidong based on the TRL method classified the maturity level of aviation composite technology ${ }^{[4]}$. Wang Gang, Chen Xiang dong and Niu Xin made the research on the coordination mechanism of aerospace products R\&D project based on TRL. This system provides reference for aerospace enterprise to build normative $R \& D$ mechanism and the corresponding technical maturity management mechanism ${ }^{[5]}$.

\subsection{Based on the theory of TRIZ technical maturity prediction research \\ The professor G. S. Altshuller of former Soviet union} found that the change trend of the number of patents related to product technology development stage, and it is concluded that there is a corresponding relationship between invention of the product quantity, level of invention, performance and profitability and s-shaped curve of technology life cycle, thus it is concluded that four standard curve ${ }^{[6]}$. Kow Alick called these four standard curves The Four Relationship Curves Operator (FRCO) ${ }^{[7]}$. Domestic scholars Li Zhiguang and Tan Runhua applied the S-curve of technology maturity prediction method of TRIZ theory to the liquid crystal display technology for the first time ${ }^{[8]}$.Wang Kun, Gao Yuhang and Yuan Shixiong used the product technology maturity prediction technology of TRIZ theory on education and game industry to predict the product technology maturity, and draw the product technology maturity prediction curve ${ }^{[9]}$.

\subsection{Based on the bibliometrics technical maturity stage research}

Roper thought the ratio between the number of journal papers and the number of conference papers could be used to analyze the product technology maturity ${ }^{[10]}$. Godin B thought we could analyze product technology maturity by changes of keywords nature in literature ${ }^{[11]}$. Martino mainly used the nature and the number of changes of relevant literature about product technology to judge technology maturity ${ }^{[12]}$. Lou Yan, $\mathrm{Fu}$ Xiaoyang, Huang Lucheng come up with a series of methods of bibliometrics to analyze technology maturity, provides a new way of thinking and methods for maturity of technology evaluation ${ }^{[13]}$.

\section{Evaluation index system of the Hybrid electric vehicle industry technology maturity}

\subsection{Design Evaluation System}

Most of the previous studies used a single indicator or a few indicators to determine the technical maturity of products; it is difficult to make a comprehensive, accurate and efficient determination of technical maturity. In view of this, this paper based on bibliometrics and patent statistical analysis, build a a multi-dimensional technology maturity evaluation index model, including the ratio of conference papers and journal papers, the ratio of EI papers and SCI papers, the ratio of the process patents and the total number of patents, the growth rate of the number of patents, the structural efficiency of patent network, patent network density, papers homogeneity, patents heterogeneity, spatial structure of patents distribution, and the ratio of patent citation and paper citation ten indexes, as shown in Table 1.

\footnotetext{
${ }^{*}$ Fund project: Henan Science and Technology Research Project (142102310141, The research on long-term development program model and key technology of Henan technology-economy system; 132102310528, Research on population resources and environment harmonious control key technology of Henan province); Key Project of National Natural Science Funds (71033002, the research on national independent innovation system internationalization theory and policy under the framework PORC).
} 
Table 1 Evaluation Index System of Technology Maturity

\begin{tabular}{|c|c|c|}
\hline Index & Computing Method & Meaning \\
\hline $\begin{array}{l}\text { the ratio of conference papers } \\
\text { and journal papers }\end{array}$ & $\begin{array}{l}\text { The number of conference papers/The number of journal } \\
\text { papers }\end{array}$ & $\begin{array}{l}\text { Reflect the importance of conference communication to } \\
\text { the journal papers }\end{array}$ \\
\hline $\begin{array}{l}\text { the ratio of EI papers and SCI } \\
\text { papers }\end{array}$ & The number of EI papers/The number of SCI papers & $\begin{array}{l}\text { Reflect the importance of the engineering application } \\
\text { relative to the basic research }\end{array}$ \\
\hline $\begin{array}{l}\text { the ratio of the process patents } \\
\text { and the total number of patents }\end{array}$ & The number of process patents/The total number of patents & $\begin{array}{l}\text { Reflect the ratio of the process patents and the product } \\
\text { technology patents }\end{array}$ \\
\hline $\begin{array}{l}\text { the growth rate of the number of } \\
\text { patents }\end{array}$ & $\begin{array}{l}\text { (The total number of patents in the } t \text { year-The total number of } \\
\text { patents in the } t-1 \text { year/The total number of patents in the } t \text { year }\end{array}$ & Reflect the growth rate of patents \\
\hline $\begin{array}{l}\text { the structural efficiency of } \\
\text { patent network }\end{array}$ & Structural holes index data calculated by Ucinet & $\begin{array}{l}\text { Reflect the degree of the patent network structure } \\
\text { interaction and network overall effectiveness }\end{array}$ \\
\hline patent network density & Whole network density index data calculated by Ucinet & Reflect the density of patent network \\
\hline papers homogeneity & $\begin{array}{l}\text { Formula: } 1 / \sum_{i=1, \ldots, m}\left(Y_{i} / Y\right)^{2} \\
\text { Ps: } Y_{i} \text { is the number of papers in the field } i, Y \text { is the total } \\
\text { number of papers. }\end{array}$ & Reflect the papers repetitiveness. \\
\hline patents heterogeneity & $\begin{array}{l}\qquad H I=\sum_{i=1, \ldots, m}\left(X_{i} / X\right)^{2} \\
\text { Formula: } \\
\text { Ps: } X_{i} \text { is the number of patents in the field } i, X \text { is the total } \\
\text { number of patents. }\end{array}$ & Reflect the degree of innovation of patents. \\
\hline $\begin{array}{l}\text { spatial structure of patents } \\
\text { distribution }\end{array}$ & $\begin{array}{l}\text { The number of patents in Japan/The total number of patents in } \\
\text { the world }\end{array}$ & Reflect the spatial concentration distribution of patents. \\
\hline $\begin{array}{l}\text { the ratio of patent citations and } \\
\text { paper citations }\end{array}$ & The number of patent citations/The number of paper citations & Reflect the importance of patents to papers \\
\hline
\end{tabular}

\subsection{Methods of data collection and index calculation}

In this paper, take the hybrid vehicles as the example of new energy vehicles, estimates the maturity of hybrid vehicles technology. According to the technical maturity evaluation model established in this paper, we should collect these data about hybrid vehicle industry, including the number of EI papers, SCI papers, conference papers, technical patents, all of patents and other data. English presentation of hybrid cars are mainly Hybrid Electric vehicle and Hybrid vehicle two kinds, which were referred to as "HEV" and "HV", other major classification codes of hybrid vehicle patents application are X21-A01D, X22-P04A, X22 -P04 and X21-A01D1, which also represents the theme of hybrid vehicle technology, as shown in Table 2. In this paper, a hybrid vehicle-related data collected in 1991-2013, the specific collection method is as follows in Table 2.
Table 2 Major Classification Codes of Hybrid Vehicle Patents Application

\begin{tabular}{|c|c|}
\hline MC & Technology Topic \\
\hline X21-A01D & Hybrid electric vehicle, use motor and engine \\
\hline X22-P04A & Electric hybrid vehicles \\
\hline X22-P04 & Hybrid vehicles \\
\hline X21-A01D1 & parallel hydraulic hybrid vehicle \\
\hline
\end{tabular}

\section{Calculation and analysis of Hybrid vehicle technical maturity}

3.1 Evaluation index system of technology maturity data set

According to the above index data collection method, calculate the each year data of hybrid vehicles technical maturity evaluation index system in 1991-2013, as shown in table 3 .

Table 3 Evaluation index system of technology maturity data set (partial data)

\begin{tabular}{|c|c|c|c|c|c|c|c|c|c|c|}
\hline Year & $\begin{array}{l}\text { the ratio of } \\
\text { conference } \\
\text { papers and } \\
\text { journal } \\
\text { papers }\left(X_{I}\right)\end{array}$ & $\begin{array}{l}\text { the ratio of } \\
\text { EI papers } \\
\text { and SCI } \\
\text { papers }\left(X_{2}\right)\end{array}$ & $\begin{array}{l}\text { the ratio of the } \\
\text { process patents } \\
\text { and the total } \\
\text { number of } \\
\text { patents }\left(X_{3}\right)\end{array}$ & $\begin{array}{l}\text { the growth } \\
\text { rate of the } \\
\text { number of } \\
\text { patents }\left(X_{4}\right)\end{array}$ & $\begin{array}{l}\text { the structural } \\
\text { efficiency of } \\
\text { patent } \\
\text { network }\left(X_{5}\right)\end{array}$ & $\begin{array}{l}\text { patent } \\
\text { network } \\
\text { density }\left(X_{6}\right)\end{array}$ & $\begin{array}{l}\text { papers } \\
\text { homogen } \\
\text { eity }\left(X_{7}\right)\end{array}$ & $\begin{array}{l}\text { patents } \\
\text { heteroge } \\
\text { neity }\left(X_{8}\right)\end{array}$ & $\begin{array}{l}\text { spatial } \\
\text { structure } \\
\text { of patents } \\
\text { distributi } \\
\text { on }\left(X_{9}\right) \\
\end{array}$ & $\begin{array}{l}\text { the ratio of } \\
\text { patent } \\
\text { citations and } \\
\text { paper } \\
\text { citations }\left(X_{10}\right)\end{array}$ \\
\hline 1991 & 0.1079 & 0.7597 & 0.2101 & 0.0080 & 0.0000 & 0.0000 & 1.6277 & 0.0933 & 0.0111 & 1.7110 \\
\hline 1995 & 0.1030 & 0.7939 & 0.2485 & -0.1605 & 0.3200 & 0.1607 & 4.2261 & 0.1846 & 0.0368 & 1.6157 \\
\hline 2000 & 0.1962 & 1.0256 & 0.8124 & 0.4661 & 0.5000 & 2.0179 & 4.9494 & 1.5346 & 0.2911 & 1.0785 \\
\hline 2001 & 0.1635 & 1.1034 & 0.8245 & -0.0146 & 0.4100 & 3.4464 & 5.5428 & 1.5152 & 0.2991 & 0.9336 \\
\hline 2005 & 0.1953 & 1.8891 & 0.9505 & 0.1589 & 0.4900 & 7.3929 & 5.4768 & 1.7580 & 0.4196 & 2.1983 \\
\hline 2010 & 0.1153 & 1.8689 & 0.9837 & 0.1506 & 0.1900 & 22.1071 & 6.4364 & 1.4035 & 0.3836 & 4.5076 \\
\hline 2013 & 0.1436 & 1.5361 & 0.9835 & 0.2084 & 0.5700 & 14.0536 & 5.1202 & 1.3288 & 0.2972 & 10.7294 \\
\hline
\end{tabular}




\subsection{Calculation and analysis of Hybrid vehicle technical maturity}

In this paper, using Principal Component Analysis (PCA) analyze the hybrid electric vehicle technology maturity index data (table 3). First take principal component analysis for ten indicators data of standardization, its 10 characteristic value and the corresponding contribution rate as shown in table 4 .

Table 4 Characteristic value and contribution rate of each index

\begin{tabular}{|c|c|c|}
\hline Index & Characteristic Value & Contribution Rate \\
\hline 1 & 5.92 & 59.202 \\
\hline 2 & 1.718 & 17.176 \\
\hline 3 & 0.824 & 8.24 \\
\hline 4 & 0.706 & 7.06 \\
\hline 5 & 0.326 & 3.263 \\
\hline 6 & 0.224 & 2.239 \\
\hline 7 & 0.176 & 1.76 \\
\hline 8 & 0.076 & 0.757 \\
\hline 9 & 0.026 & 0.257 \\
\hline 10 & 0.005 & 0.046 \\
\hline
\end{tabular}

The table 4 shows that the contribution rate of first two indicators of were $59.2 \%, 17.17 \%$, their cumulative contribution rate is $76 \%$, thus it can be used for make evaluation of each index. By principal component analysis (PCA), the first two principal components and the weight of each index as shown in table 5.

Table 5 First Two Principal Components and the Weight of Each Index

\begin{tabular}{|l|c|c|c|}
\hline Index & $\begin{array}{l}\text { First principal } \\
\text { components }\end{array}$ & $\begin{array}{l}\text { Second principal } \\
\text { components }\end{array}$ & weight \\
\hline $\begin{array}{l}\text { the ratio of conference } \\
\text { papers and journal papers }\end{array}$ & 0.270 & 0.494 & 0.1347 \\
\hline $\begin{array}{l}\text { the ratio of EI papers and } \\
\text { SCI papers }\end{array}$ & 0.373 & -0.186 & 0.1039 \\
\hline $\begin{array}{l}\text { the ratio of the process } \\
\text { patents and the total } \\
\text { number of patents }\end{array}$ & 0.400 & -0.039 & 0.1266 \\
\hline $\begin{array}{l}\text { the growth rate of the } \\
\text { number of patents }\end{array}$ & 0.255 & 0.030 & 0.0859 \\
\hline $\begin{array}{l}\text { the structural efficiency of } \\
\text { patent network }\end{array}$ & 0.132 & 0.511 & 0.0913 \\
\hline patent network density & 0.320 & -0.400 & 0.0664 \\
\hline papers homogeneity & 0.338 & 0.108 & 0.1203 \\
\hline patents heterogeneity & 0.385 & 0.108 & 0.1356 \\
\hline $\begin{array}{l}\text { spatial structure of patents } \\
\text { distribution }\end{array}$ & 0.392 & 0.033 & 0.1308 \\
\hline $\begin{array}{l}\text { the ratio of patent } \\
\text { citations and paper } \\
\text { citations }\end{array}$ & 0.166 & -0.523 & 0.0046 \\
\hline
\end{tabular}

Then, by the original data and the weight of each index, calculate the standard value, set up the following technical maturity formula as shown in (1), it can measure hybrid vehicle technical maturity index for every year.
The evaluation model of the maturity of the technology:

$$
I=\sum_{i=1}^{10} \theta_{i} X_{i} / X_{i 0}
$$

In formula (1), $I$ is the technology maturity, $X_{i}$ is the actual value of the index $\mathrm{i} ;{ }^{\theta_{i}}$ is the weight of the index $\mathrm{i}$, it can be calculate by principal component analysis; $X_{i 0}$ is the standard value of the index $i$.

In figure 1 can be found, the hybrid vehicle technology in the world got mature in 2003, and after 2009 because of a new technological breakthrough, makes technical maturity index appeared a downward trend, it is realistic. In fact, the Toyota Prius hybrid cars released 1997 technical maturity is reached $58 \%$.

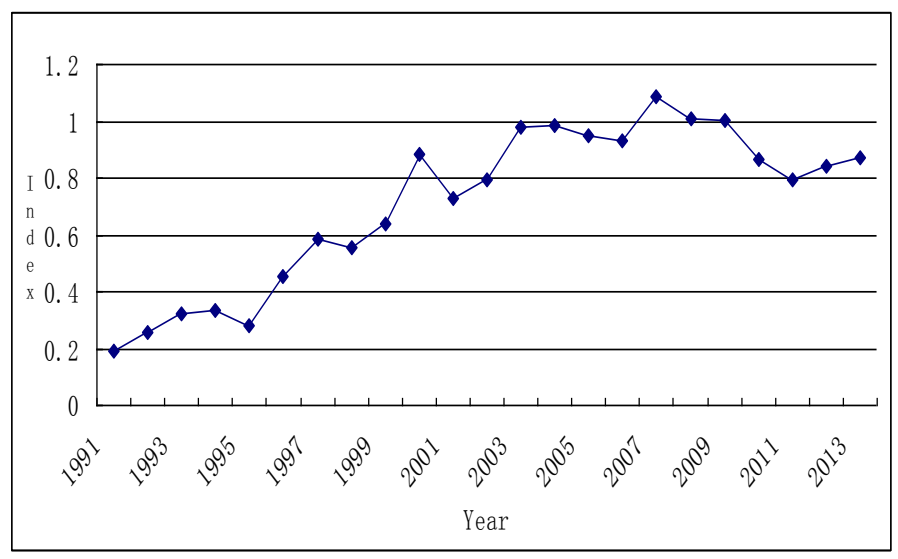

Figure 1 The tendency of the Hybrid electric vehicle technology maturity indicators

\section{Conclusion}

(1)Based on the TRL theory, TRIZ theory, scientometrics, patentometrics and other theories and methods, learn from analysis methods such as Fisher-Pry model, a multi-dimensional technology maturity evaluation index system model can be constructed include the ratio of conference papers and journal papers, the ratio of EI papers and SCI papers, the ratio of the process patents and the total number of patents, the growth rate of the number of patents, the structural efficiency of patent network, patent network density, papers homogeneity, patents heterogeneity, spatial structure of patents distribution, and the ratio of patent citation and paper citation ten indexes.

(2) This multi-index evaluation system model overcome the shortcomings of single indicators evaluation system; make a more comprehensive evaluation of technology maturity. Hybrid vehicles estimates indicate that the world's hybrid vehicle technology has matured in general in 2003. And when Toyota released the hybrid vehicle Prius in 1997, the hybrid cars technology maturity of the world had got $58 \%$. 
(3) However, later in 2009, hybrid vehicle technology has made new breakthroughs on scientific research. The proportion of Japanese patent, the patent network density, the ratio of EI papers and SCI papers, the ratio of the conference papers and journal articles, papers homogeneity and other indicators declined, indicating that the hybrid vehicle technology innovation has entered a new period.

(4) From the overall perspective of the technology track, including nickel-metal hydride battery technology track(such as Toyota) and lithium-ion battery technology tracks (such as BYD), estimate the hybrid vehicles technical maturity around the world. It is the world's overall estimates. For a technical track, for example, nickel-metal hydride battery technology track, its technology has reached maturity period much earlier than 2003; while for the lithium-ion battery technology track, the technology got mature period later than 2003.

\section{References}

[1] John C. Mankins. (2009). Technology readiness assessments: A Retrospective. Acta Astronautica, 65 (9), 1216-1223.

[2] Mankins, J. C. (2002). Approaches to strategic Research and Technology(R\&T) Analysis and Road Mapping. Acta Astronautica, 51 (1), 3-21.
[3] Huang Lu-cheng, Zhao Zhi-hua, \& Fu Xiao-yang. (2010). Review on the technology maturity of product. Scientific management research, 28 (02), 38-41, 54.

[4] Lan Yuan-pei, \& Guan Zhi-dong. (2009). The Assessment of Aviation Composite Material Technology Maturity Based on the TRL. Civil Aircraft Design and Research. (S1), 81-83.

[5] Wang Gang, Chen Xiang-dong, \& Niu Xin. (2012). The coordination system for R\&D projects in aviation and aerospace sectors based on TRL. Science reserch management, 33 (07), 59-66.

[6] Altshuller. (2006). Social indicators for sustainable project and technology life cycle management in the process industry. The International Journal of Life Cycle Assessment, 11 (1), 3-15.

[7] James F\& Kowalick. Technology Forecasting Processes Using AFTER96(Algorithm for Forecasting Technology-Evolution Roadmaps) [EB/OL]. [1997-2-2]. http://www.triz-journal.com/technologyforecasting-triz/

[8] Li Zhi-guang, \& Tan Run-hua. (2012). Maturity grade of LCD technology based on TRIZ. Chinese Journal of Liquid Crystals and Displays, 27 (06), 852-855.

[9] Wang Kun, Gao Yu-hang, \& Yuan Shi-xiong. (2014). The Prediction of Serious Games Product Technology Maturity Based on TRIZ. Heilongiiang Science, 5 (04), 162.

[10] Porter A L. Roper A T. Mason T W. ET al. Forecasting and Management of Technology. New York: Wiley. 1991: 11-14

[11] Godin B. (1996). Research and the Practice of Publication in Industries. Research Policy. (25), 587-606

[12] Martino J P. (2003). A Review of Selected Recent Advances in Technological Forecasting. Technological Forecasting \& Social Change, 70 (8), 719-733

[13] Lou Yan, Fu Xiao-yang, \& Huang Lu-chen. (2010). Based on the literature metrology technology maturity research and empirical analysis. Statistics and decision, (19), 99-101. 